\title{
Differential Cholinergic Regulation of Dopamine Release in the Dorsal and Ventral Neostriatum of the Rat: An in vivo Microdialysis Study
}

\author{
W. T. O'Connor, ${ }^{1}$ K. L. Drew, ${ }^{2}$ and U. Ungerstedt ${ }^{t}$ \\ 'Department of Physiology and Pharmacology, Division of Pharmacology, Karolinska Institute, S171-77 Stockholm, \\ Sweden and ${ }^{2}$ Institute of Arctic Biology, University of Alaska, Fairbanks, Alaska
}

We used in vivo microdialysis to investigate the effects of local perfusion with the AChE inhibitor neostigmine on the basal and haloperidol evoked increase in dialysate dopamine levels in the dorsolateral and fundus striata of the bilaterally implanted halothane anaesthetized rat. In the absence of neostigmine basal dopamine was consistently higher in the dorsolateral striatum compared with the fundus striati. Local perfusion with neostigmine (10 and 100 $\mu \mathrm{M})$ increased basal dopamine in the fundus striati compared to the contralateral (control) side but not in the dorsolateral striatum. In the absence of neostigmine haloperidol (0.05-0.5 $\mathrm{mg} / \mathrm{kg}$, s.c.) increased dopamine release in both the dorsolateral and fundus striata. However, local perfusion with neostigmine (10 $\mu \mathrm{M})$ attenuated this increase in the dorsolateral striatum at all doses of haloperidol while only the effect of the highest $(0.5 \mathrm{mg} / \mathrm{kg})$ dose of haloperidol was counteracted in the fundus striati. Both the basal and haloperidol $(0.25 \mathrm{mg} / \mathrm{kg})$ induced increase in dopamine release in the control (no neostigmine) and neostigmine $(+10 \mu \mathrm{M})$ treated dorsolateral striata were abolished following local perfusion with tetrodotoxin (1 $\mu \mathrm{M})$.

The data demonstrate that the introduction of neostigmine into the neostriatum selectively increases basal DA levels in the fundus striati and strongly counteracts the haloperidol evoked DA release in the dorsolateral striatum and thus provide strong evidence for a differential cholinergic regulation of striatal DA release in vivo. In addition, we demonstrate that the stimulatory and inhibitory effects of neostigmine operate independently and have a regional specificity within the neostriatum.

[Key words: neostigmine, dopamine, haloperidol, microdialysis, neostriatum, dorsolateral, fundus]

Biochemical and electrophysiological studies on the mechanism of action of neuroleptic drugs provide strong evidence that the antipsychotic effect of these drugs is thought to be mediated via an action on the $A_{10}$ dopamine (DA) projection to the ventral neostriatum and frontal cortex while the extrapyramidal motor

\footnotetext{
Received Dec. 16, 1994; revised Aug. 18, 1995; accepted Aug. 24, 1995.

We acknowledge the financial support provided by grants from the Ake Wiberg Stiftilse, the Stanley Foundation, and the Welcome Trust to W.T.O.; by a USPHS National Research Service Award NS08240 and NIH Grant AG09483 to K.L.D.; and by a USPHS Grant MH44211 (Neuroscience Center for Research in Schizophrenia) to U.U.

Correspondence should be addresssed to Dr. W. T. O'Connor at the above address.

Copyright $(\mathcal{C} 1995$ Society for Neuroscience $0270-6474 / 95 / 158353-09 \$ 05.00 / 0$
}

side effects are thought to be mediated via an action on the $\mathrm{A}_{9}$ DA projection to the dorsal neostriatum (Andén and Stock 1973; Costall and Naylor, 1976; Chiodo and Bunney, 1983; White and Wang 1983). Anticholinergic activity reduces extrapyramidal side effects without decreasing antipsychotic efficacy and may distinguish atypical and typical antipsychotics (Snyder et al., 1974). The purpose of the present study was to investigate the cholinergic regulation of dopamine release within subregions of mammalian striatum.

Until recently the caudate putamen was considered to be a homogenous structure. This region was distinguished from the nucleus accumbens on the basis of their respective $A_{9}$ and $A_{10}$ DA afferents (Dahlstrom and Fuxe, 1964). However it is increasingly evident that the caudate nucleus is not a homogenous structure (Nauta, 1986). Anatomically the ventromedial striatum including the fundus striati (Paxinos and Watson, 1982) and the nucleus accumbens is distinguished from the dorsolateral striatum by afferents originating from limbic structures (e.g., the hippocampus and the amygdala) and from structures implicated in the circuitry of the limbic system (e.g., prefrontal cortex and DA afferents from the ventral tegmental area $\left(A_{10}\right)$ (Nauta, 1986). The dorsolateral striatum by contrast, is characterized by glutamatergic afferents originating from the sensorimotor cortex and DA afferents from the substantia nigra $\left(A_{9}\right)$. This striatal subregion receives only sparse inputs of limbic origin (cf. Nauta 1986) and plays a primary role in the "motor circuit" mediating sensorimotor functions particularly the initiation of voluntary motor acts. Regional difference in $\mathrm{D}_{2}$ receptor density and cholinergic activity has also been reported in the striatum with higher $\mathrm{D}_{2}$ receptor binding (Joyce and Marshall, 1987), AChe activity (Joyce and Marshall, 1987; Loopuijt 1989) and dialysate ACh levels (O'Connor et al., 1991a; Osborne et al., 1994) in the dorsolateral striatum.

A major function of striatal acetylcholine $(\mathrm{ACh})$ is the regulation of DA release via both nicotinic and muscarinic receptors. Choline acetyltransferase (CAT)-labeled terminals also synapse on tyrosine hydroxylase (TH)-labeled terminals in the dorsal and ventral striatum (Pickle and Chan, 1990). In fact, ACh was the first neurotransmitter shown to affect striatal DA release in vitro (Besson et al., 1969) and since then both in vitro and in vivo studies have provided evidence for a cholinergic modulation of DA release in the neostriatum (Giorguieff et al., 1977; De Bellerroche et al., 1982; Damsma et al., 1988; Xu et al., 1989; Rapier et al., 1990; Farber et al., 1993). Recent binding and autoradiographic studies in mammalian brain demonstrate that the majority $(75 \%)$ of striatal muscarinic receptors are of the 


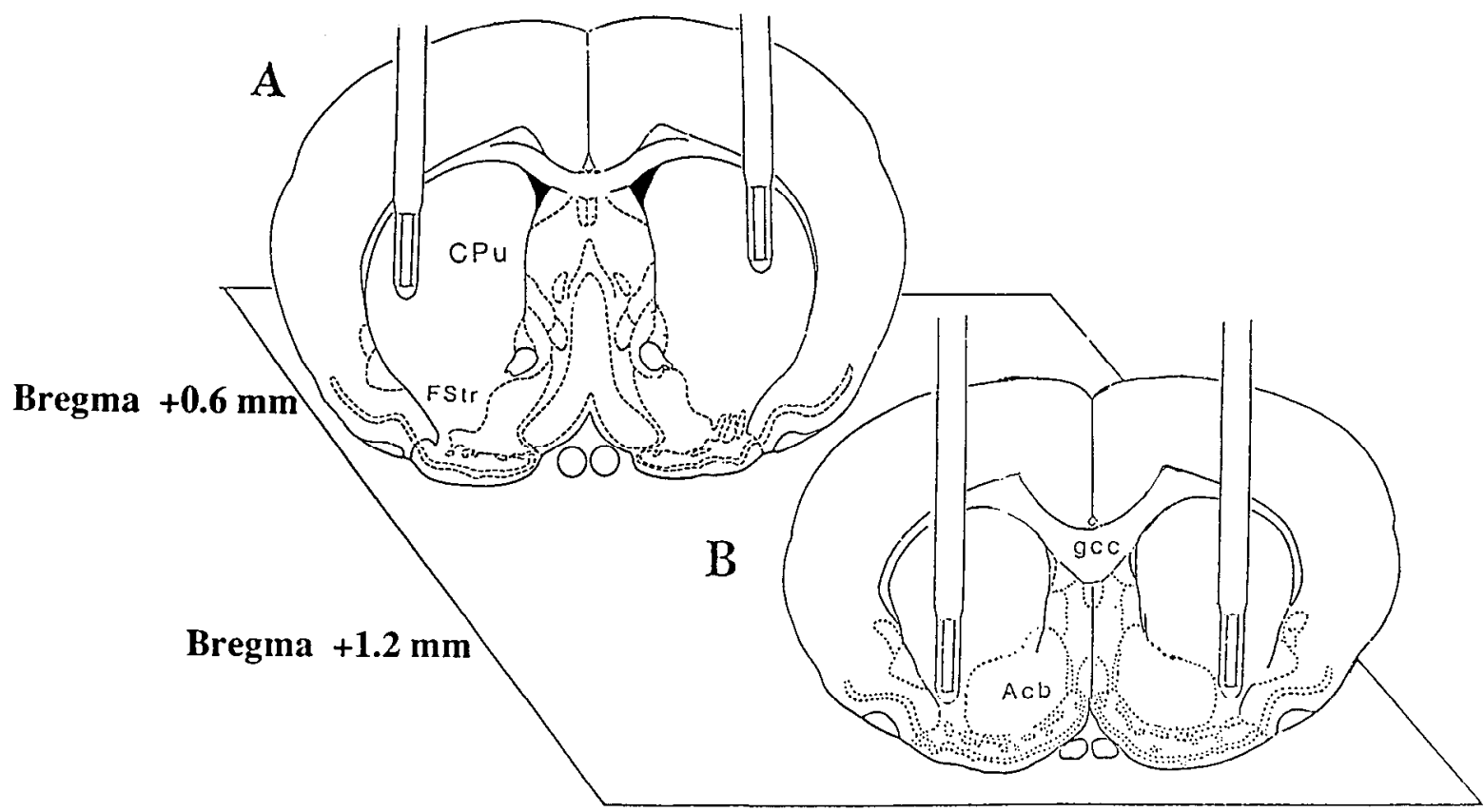

Figure 1 . Location of the microdialysis probe in the right (no neostigmine) and left ( + neostigmine) $(A)$ dorsolateral and $(B)$ fundus striata. Abbreviations are as follows: $A c b$, nucleus accumbens; $C P u$, caudate putamen; FStr, fundus straiti; gcc, genu of the corpus callosum. Probes were implanted bilaterally in either the dorsolateral or fundus striata. For full coordinates, see Materials and Methods.

excitatory $M_{1}, M_{3}$, and $M_{5}$ subtypes and the less numerous and inhibitory $M_{2}$ and $M_{4}$ subtypes (Hammer and Giachetti, 1982; Olianas et al., 1982; Cortes and Palacios, 1986; Cortes et al., 1986; Mash and Potter, 1986; Spencer et al., 1986). Both the muscarinic and the less common and stimulatory nicotinic (also five subtypes) receptors are localized both pre- and postsynaptically (Cooper, 1994; Jerusalinski et al., 1995) and converging data suggest that both muscarinic and nicotinic receptors are located on the DA terminals in both dorsal and ventral neostriatum (De Belleroche et al., 1979, 1982; Gurwitz et al., 1980; Suga, 1980; Xu et al., 1989). However, pharmacological agents are not highly selective for particular subtypes, making investigations on the functional significance of the subtypes difficult. Striatal ACh has been shown to facilitate evoked striatal DA release via both nicotinic and muscarinic $M_{1}$ receptors. $A C h$ can also reduce evoked striatal DA release (Westfal 1974a,b) via $\mathrm{M}_{2}$ receptor activation giving rise to the concept of a dual cholinergic regulation of striatal DA release resembling the cholinergic modulation of noradrenaline release in peripheral nerves (Muscholl 1979).

Based on the above findings, we tested the hypothesis for a difference in the cholinergic regulation of DA release in the dorsolateral and ventromedial (fundus) neostriatum. Towards this aim, we monitored the effects of local perfusion with the indirect cholinergic agonist neostigmine, on basal dialysate DA levels and following acute, systemic administration of haloperidol (Christensen et al., 1984; Grabiel et al., 1989) in the dorsolateral and fundus neostriata.

\section{Materials and Methods}

Brain microdialysis and surgery. Sixty-two male rats weighing 330 390 gm (Sprague--Dawley, Alab, Sollentuna, Sweden) were used in this study. The animals were allowed free access to water and standard laboratory food in a temperature controlled environment and were kept on a $12 \mathrm{hr}$ light/dark cycle. The experimental protocols performed in the present study were approved by the Swedish committee for ethical ex- periments on laboratory animals, license No. N128. Rats were anaesthetized with halothane (1.5\% halothane/air mixture delivered at 1.4 liter/min) and placed in a stereotaxic frame (Kopf). Body temperature was continuously maintained at $37^{\circ} \mathrm{C}$ using a temperature controller (CMA 150, Carnegie Medicin, AB, Stockholm, Sweden). After exposure of the skull and drilling of a burr hole ( $1 \mathrm{~mm}$ diam), concentric microdialysis probes (CMA 12, O.D. $0.5 \mathrm{~mm}, 2 \mathrm{~mm}$ membrane, Carnegie Medicin $A B$, Stockholm, Sweden) were stereotaxically implanted into the left and right dorsolateral or fundus striata according to the atlas of Paxinos and Watson (1982) (dorsolateral striatum coordinates, $\mathrm{A}+0.6, \mathrm{~L} \pm 3.5, \mathrm{~V} 5.5$; and fundus striati, $\mathrm{A}+1.2, \mathrm{~L} \pm 2.7, \mathrm{~V} 7.5 \mathrm{~mm}$ relative to bregma; incisor bar -2.5 ). Thus, there were two groups of rats under investigation, one group received bilateral probe implants in the dorsolateral striatum and a second group received bilateral probe implants in the fundus striati (Fig. 1). The probes were perfused at a rate of $2 \mu \mathrm{l} / \mathrm{min}$ with commercial Baxter's Ringer solution $(147.0 \mathrm{mM}$ $\mathrm{Na}^{+}, 2.4 \mathrm{mM} \mathrm{Ca}^{2+}, 156 \mathrm{mM} \mathrm{Cl}^{-}, 4.0 \mathrm{mM} \mathrm{K}{ }^{+}, \mathrm{pH}$ 6.0; Baxter $\mathrm{A} / \mathrm{S}$, Halden, Norway). Neostigmine $(1,10$, or $100 \mu \mathrm{M})$ was included in the perfusion medium on the left side. The collection of perfusate samples for assay commenced $120 \mathrm{~min}$ after probe implantation. Samples were collected every $30 \mathrm{~min}$ and $40 \mu \mathrm{l}$ was analyzed for D $\Lambda$. In vitro recov ery (mean \pm SEM \%) across the probe membrane for DA was $11.5 \pm$ 0.7 . The DA levels reported in the present study are not corrected for recovery (Hsiao et al., 1990).

Experimental protocol. This investigation was divided into three experiments. The effects of local perfusion with neostigmine were studied on (1) basal dialysate DA levels and (2) haloperidol stimulated DA levels in the left dorsolateral and fundus striata while the contralateral side acted as the control. In addition, (3) the tetrodotoxin sensitivity of both the basal and haloperidol induced increase in DA release in the control (no neostigmine) and neostigmine $(10 \mu \mathrm{M})$ treated dorsolateral striata was also investigated. The microdialysis probes were connected to a microinfusion pump via a syringe selector (CMA 111) which allowed the appropriate perfusion medium to be selected.

Neostigmine. Neostigmine was added to the perfusion medium to inhibit AChE and to elevate synaptic ACh levels. The selected concentration of neostigmine $(1,10$, or $100 \mu \mathrm{M})$ was included in the perfusion medium on the left side prior to probe implantation and was infused throughout the experiment. Neostigmine was chosen over physostigmine because of its more local effect in the interstitial compartment by virtue of its poor lipophilicity and its lack of sensitivity to $\mathrm{pH}$ and light (Koelle, 1975). 


\section{A}

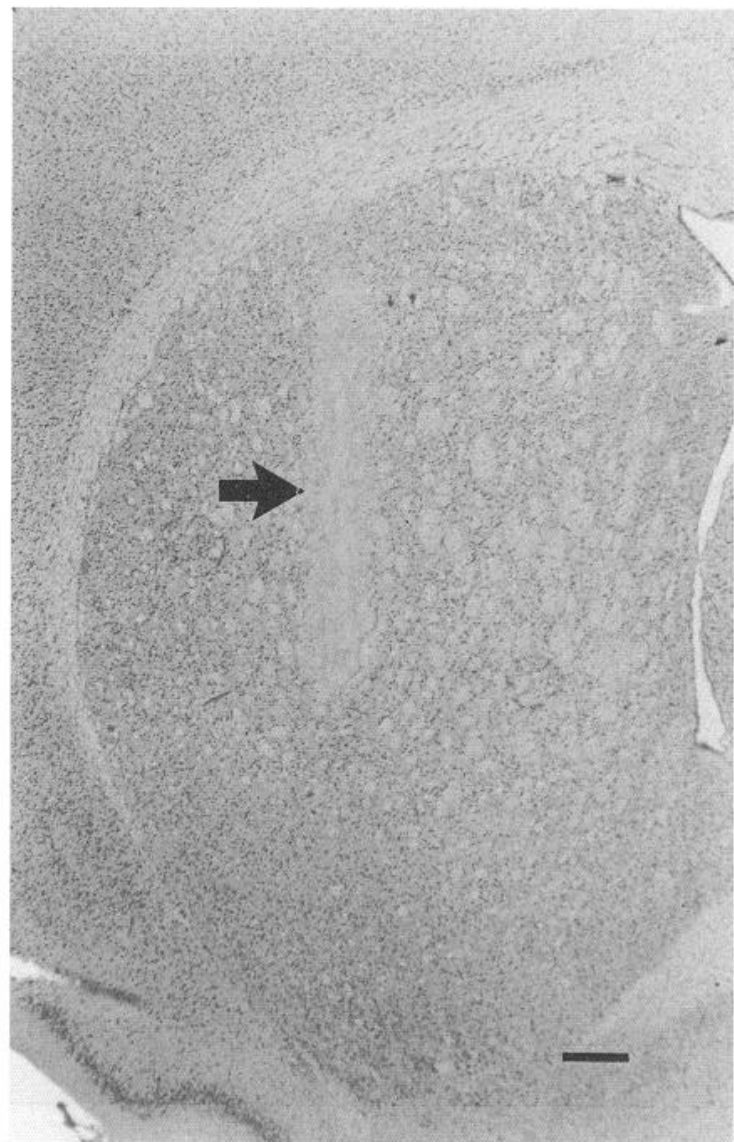

$\mathrm{B}$

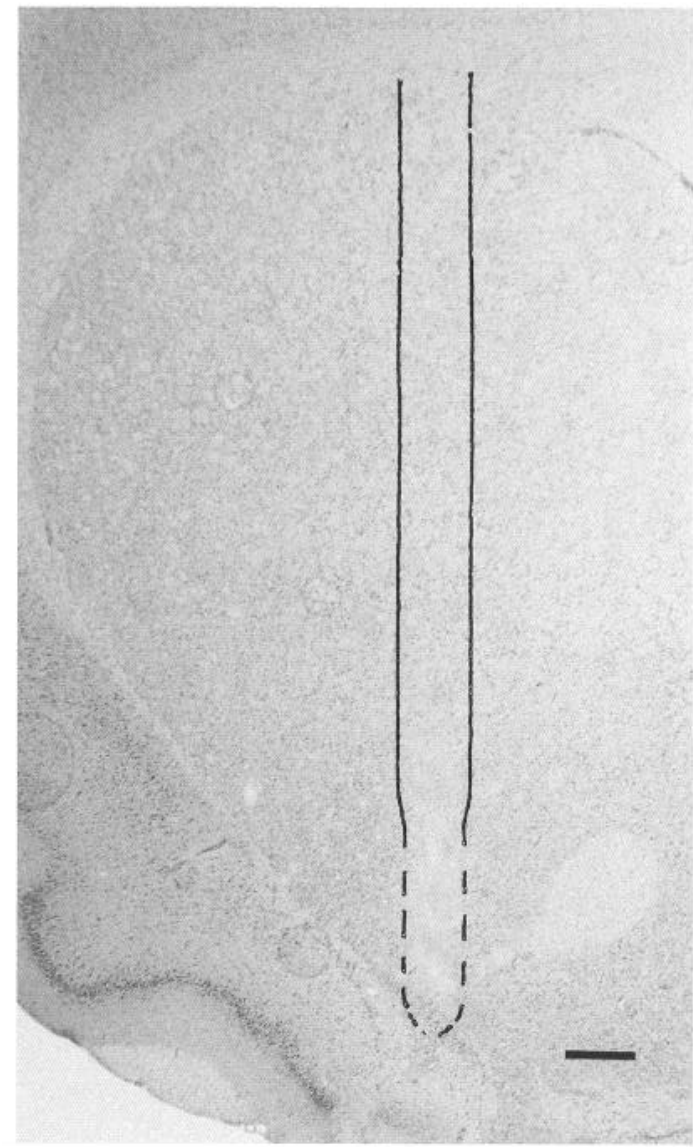

Figure 2. A, Photomicrograph from a cresyl violet-stained section through the dorsolateral striatum showing the track left by the microdialysis membrane (arrow). B, Section through the fundus striati. The schematic drawing of the probe represents its actual size and position. The dialysis membrane corresponds to the part delimited by the dashed lines. Scale bar: $500 \mu \mathrm{m}$.

Haloperidol. At least three stable DA samples were obtained ( $90 \mathrm{~min})$ after which the selected dose of haloperidol $(0.05,0.25$, or $0.5 \mathrm{mg} / \mathrm{kg})$ or haloperidol vehicle was administered as a single subcutaneous injection in the hind limb area.

Tetrodotoxin. The reversible antagonist of voltage dependent $\mathrm{Na}^{+}$ channels, tetrodotoxin, (TTX) was perfused locally into both the control and neostigmine treated dorsolateral striata in order to study the firing dependence of the basal and haloperidol induced increases in dialysate DA levels. TTX $(1 \mu \mathrm{M})$ was included in the perfusion medium on both the control and neostigmine $(10 \mu \mathrm{M})$ treated sides after three stable basal DA values $(90 \mathrm{~min}$ ) were recorded and continued to be perfused until the end of the experiment $(270 \mathrm{~min}) .90 \mathrm{mins}$ following the start of TTX perfusion, either haloperidol $(0.25 \mathrm{mg} / \mathrm{kg}$, s.c. $)$ or vehicle was administered.

Dopamine analysis. The perfusate samples $(40 \mu \mathrm{l})$ were placed into a refrigerated microsampler/autoinjector (CMA200/240) and were automatically injected. Reverse phase HPLC with electrochemical detection was used to assay DA. The method has been described previously (Drew et al., 1989). The composition of the mobile phase was $0.132 \mathrm{M}$ $\mathrm{NaH}_{2} \mathrm{PO}_{4}, 9 \mathrm{~mm}$ EDTA, $1.2 \mathrm{mg}$ sodium octane sulfonate, and $12 \%$ methanol, $\mathrm{pH}=3.8$. The flow rate of the mobile phase was $0.5 \mathrm{ml} /$ min. The limit of detection was 0.02 pmol DA.

Verification of cannula placement. At the end of each experiment rats were killed with an overdose of halothane. The brain was removed and cut on a Leitz freeze microtome (Germany) and the placement of the probe verified by microscopic examination (Fig. 2). Those animals displaying either improper probe implantation or excessive damage were omitted from the study.
Data presentation and statistical analysis. Data are reported as percent of basal values (calculated as mean of the two samples before haloperidol. Data are calculated as means $\pm \operatorname{SEM}(N=3-7)$. Data were analysed with a two way analysis of variance with region (dorsolateral and fundus) and concentration (neostigmine) and dose (haloperidol) treated as between subject variables and time treated as a within subjects variable. Significant $(P<0.05)$ dose time interactions (DT) were followed by a one way analysis of variance for each dose and subsequent Newman-Keuls post-hoc comparison (Crisp Crunch) or a paired $t$ test where indicated.

Chemicals. Neostigmine methyl sulfate [(3-dimeethylcarbamoxyphenyl) trimethyl-ammonium methyl sulfate], (N-2126, Sigma Chemical Company, St. Louis, MO) and tetrodotoxin (TTX) (Janssen Pharmaceutica, Belgium) were dissolved in Ringer's and water, respectively, and stored at $-80^{\circ} \mathrm{C}$ as $1 \mathrm{~mm}$ stock and on the day of the experiment was added to the perfusion medium to give the desired concentration. Haloperidol (Haldol, Janssen Pharmaceutica, Beerse, Belgium) was diluted to the required concentrations in water and administered as a single subcutaneous injection in a volume of $1 \mathrm{mg} / \mathrm{kg}$. Haloperidol placebo (Janssen Pharma AB, V. Frölunda) was employed as the vehicle.

\section{Results}

There was no difference in basal dialysate DA levels in the dorsolateral or fundus striata between the left and right sides in the bilateral control group (i.e., in the absence of neostigmine) (Table 1). In addition, there was no difference in the maximal 
Table 1. The effect of neostigmine on basal dialysate dopamine levels in the dorsolateral and fundus striata

\begin{tabular}{cccc} 
Control & Neostigmine & Dose $(\mu \mathrm{M})$ & $(N)$ \\
\hline Dorsolateral striatum & & & \\
$6.75 \pm 0.99$ & $6.54 \pm 1.41$ & 0 & 8 \\
$7.05 \pm 1.35$ & $8.45 \pm 1.79$ & 1 & 5 \\
$4.52 \pm 1.10$ & $4.12 \pm 0.95$ & 10 & 7 \\
$11.92 \pm 2.72$ & $10.30 \pm 1.72$ & 100 & 4 \\
Fundus striati & & & \\
$1.47 \pm 0.43$ & $1.62 \pm 0.45$ & 0 & 7 \\
$4.82+2.15$ & $3.62+1.15$ & 1 & 4 \\
$1.20 \pm 0.40$ & $2.72 \pm 0.45^{*}$ & 10 & 4 \\
$6.15 \pm 1.20$ & $9.80 \pm 0.97^{*}$ & 100 & 3
\end{tabular}

Values (means \pm SEM) are expressed in nanomolar concentrations and represent the mean of two stable basal levels $(60 \mathrm{~min})$. Data are presented as mean \pm SEM. Neostigmine $(1,10$, or $100 \mu \mathrm{M})$ was included in the perfusion medium on left side. A group of rats without neostigmine on either side acted as the bilateral control in the dorsolateral or fundus striata. Statistical analysis was performed by a two way $\Lambda$ NOV $\Lambda$ with side (neostigmine) treated as a within subjects variable and followed by a paired $t$ test. $N$ represents the number of animals in each group.

$* P<0.05$ versus control side (no neostigmine) fundus striati.

haloperidol $(0.25 \mathrm{mg} / \mathrm{kg})$ induced increase in dialysate DA levels in the right and left dorsolateral striata $(155 \pm 31 \%$ and $152 \pm$ $23 \%$, respectively) and in the right and left fundus striata (174 $\pm 30 \%$ and $224 \pm 30 \%$, respectively) in this control group. However, basal DA levels were consistently higher in dorsolateral striatum $(4.85 \pm 0.07 \mathrm{nM})$ compared with the fundus striati $(1.75 \pm 0.25 \mathrm{nM})(p=0.024)$ (Table 1$)$. A large variability in dialysate DA levels was observed during the first $120 \mathrm{~min}$ of perfusion (not shown), probably reflecting tissue disruption resulting from probe implantation and equilibration between the dialysate and the extracellular fluid compartments. DA release stabilized $120 \mathrm{~min}$ after probe implantation and remained constant over the course of the experiment $(300 \mathrm{~min})$.

\section{Effect of neostigmine on dialysate dopamine levels}

Local perfusion with neostigmine $(10$ and $100 \mu \mathrm{M})$ increased basal DA levels in the fundus straiti $(p=0.0155)$ but not the dorsolateral striatum compared to the control (no neosigmine) side $(p<0.05)$ (Fig. 3A,B). Thus, when compared to the control side, only the fundus striati showed a significant neostigmine induced increase in basal DA levels. There was an increase in basal DA levels on both sides in fundus $(p<0.001)$ and dorsolateral striata $(p<0.05)$ at the highest $100 \mathrm{mM}$ concentration of neostigmine compared with the two lower concentrations.

\section{Effect of haloperidol on dialysate dopamine levels}

Acute haloperidol administration $(0.05,0.25$, and $0.5 \mathrm{mg} / \mathrm{kg}$, s.c.) was associated with an increase in DA release in both the control (no neostigmine) dorsolateral (DT $=0.012$ ) (Fig. 4A) and fundus striata (DT $=0.0102$ ) (Fig. $5 A$ ). Dialysate DA levels were elevated in the first fraction $(30 \mathrm{~min}$ ) following haloperidol and continued to rise until the end of the experiment (150 min).

\section{Effect of neostigmine on the haloperidol response}

Local perfusion with neostigmine $(10 \mu \mathrm{M})$ was associated with a profound counteraction of the haloperidol induced increase in DA release in the dorsolateral striatum at all the doses of haloperidol tested (Fig. $4 B$ ). In the fundus striati the effects of the highest $(0.5 \mathrm{mg} / \mathrm{kg}$, s.c. $)$ dose of haloperidol was significantly

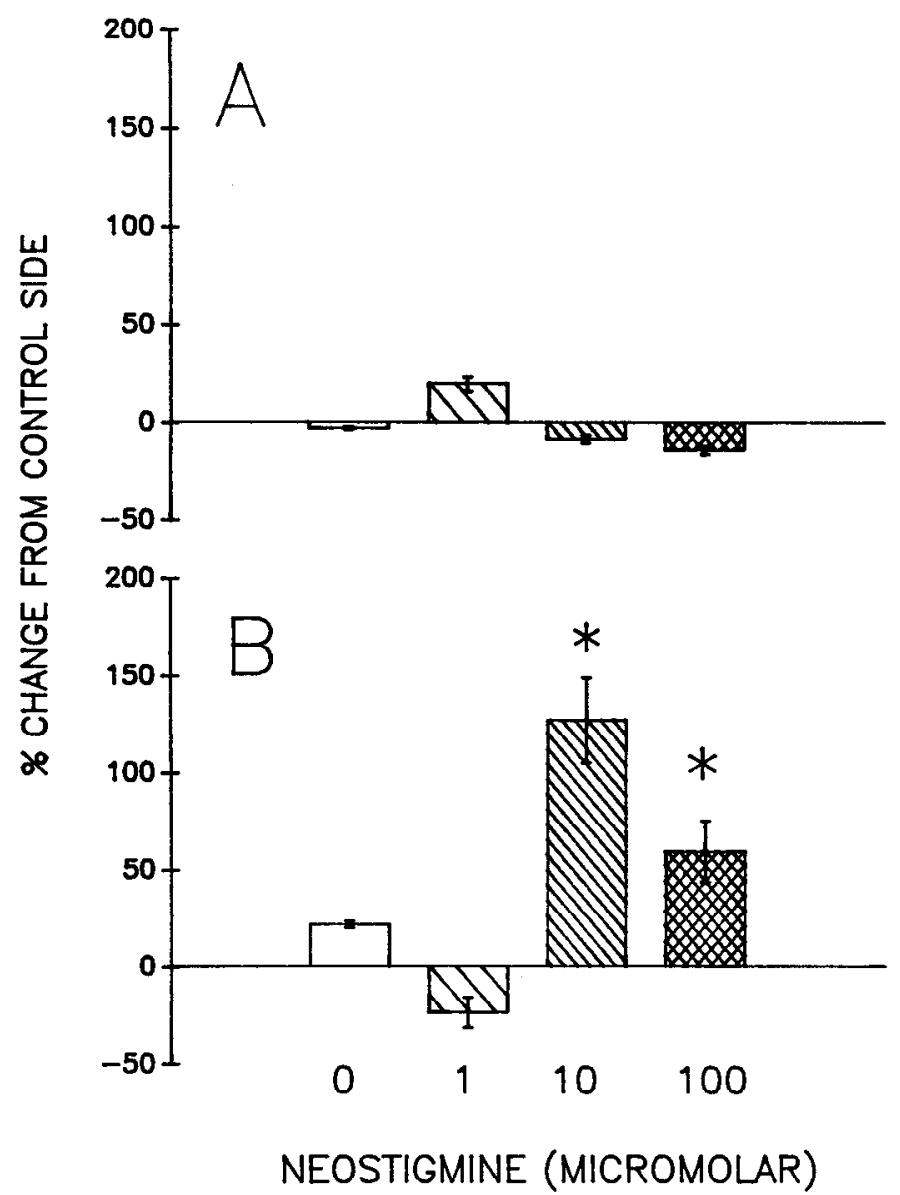

Figure 3. Effect of local perfusion with neostigmine on basal dialysate dopamine $(D A)$ levels in $(A)$ the dorsolateral striatum and $(B)$ the fundus striati of halothane anesthetized rats in 30 min Ringer's perfusate fractions. The perfusate contained either $1 \mu \mathrm{M}$ (wide hatch), $10 \mu \mathrm{M}$ (narrow hatch) or $100 \mu \mathrm{M}$ (cross hatch) neostigmine which was included in the perfusion medium on the left side prior to probe implantation and continued to be perfused until the end of the experiment. A group of rats without neostigmine on either side acted as the bilateral control (open bar) in the dorsolateral or fundus striata. Data are expressed as percent change from the basal levels on the contralateral control side. The change in dialysate DA levels are expressed as percent change from the levels on the control (no neostigmine) side. See Table 1 for absolute DA levels. Neostigmine significantly increased basal DA levels in the fundus striati compared to the control (no neostigmine) side. Each data point $(N=3-7)$ per group represents the mean \pm SEM. Statistical analysis was performed by a paired Student's $t$ test. ${ }^{*}, P<0.05$ versus the control (no neostigmine) side.

counteracted by neostigmine but this inhibition was not observed at the lower the 0.05 and $0.25 \mathrm{mg} / \mathrm{kg}$ doses of haloperidol (Fig. $5 B$ ). When present, the counteraction of the haloperidol induced increase in DA release by neostigmine was already evident in the first fraction $(30 \mathrm{~min})$ following haloperidol and was still present at the end of the experiment $(250 \mathrm{~min})$.

Intrastriatal perfusion with TTX $(1 \mu \mathrm{M})$ on both the control (no neostigmine) and left (10 $\mu \mathrm{M}$ neostigmine) sides decreased basal dialysate DA levels by $70 \%$ within two fractions $(60 \mathrm{~min})$ $(P<0.001)$ and blocked the effect of haloperidol $(0.25 \mathrm{mg} / \mathrm{kg}$ s.c.) on dialysate DA levels both in the absence and presence of neostigmine in the pertusion medium (Fig. $6 A, B$ ).

\section{Discussion}

This study was undertaken to test the hypothesis for a difference in the cholinergic regulation of DA release in the dorsolateral 
and fundus neostriata which may be relevant to the antipsychotic efficacy and neuroleptic properties of antipsychotic drugs. Toward this aim we used in vivo microdialysis (Ungerstedt, 1991) to monitor the effects of local perfusion with neostigmine on both basal and haloperidol evoked DA release in the acutely implanted halothane anaesthetised rat. The results suggest a dorsolateral/ventromedial heterogeneity in the neostriatum which markedly influcnces how basal and haloperidol-induced DA release respond in the presence of increased cholinergic tone.

\section{Basal dialysate dopamine levels}

We report a regional difference in basal dialysate DA levels within the neostriatum with consistently higher levels in the dorsolateral striatum compared to the fundus striati. This difference is consistent with previous findings (O'Connor et al., 1989; Drew et al., 1990) and strengthens the evidence for a dorsolateral-ventromedial heterogeneity in DA tone within the neostriatum (Joyce and Marshall 1985; Nauta, 1986; Grenhoff et al., 1988).

\section{Effect of neostigmine on dialysate dopamine levels}

Local perfusion with the $10 \mu \mathrm{M}$ and $100 \mu \mathrm{M}$ concentrations of neostigmine increased basal DA levels in the fundus striati but not in the dorsolateral striatum suggesting that in contrast to the well documented DA regulation of $\mathrm{ACh}$ release in the dorsal and ventral striatum (Bertorelli and Consolo, 1990; Damsma et al., 1990; Stoof et al., 1992; Di Chiara et al., 1994) activation of local cholinergic receptors in these striatal subregions differentially regulates basal DA release. The highest $(100 \mu \mathrm{M})$ concentration of neostigmine increased basal DA in both striatal subregions compared to the two lower concentrations (Table 1). However, due to the large inter-group difference in basal DA levels it is not possible determine if this was an effect of neostigmine per se.

Previous microdialysis studies report a diminished ability of concentric (and U-shaped) cannulae to detect extracellular ACh from the dorsal striatum compared with the transversal design (Damsma, 1987a, 1988). Thus, higher (e.g., $10 \mathrm{~mm}$ ) concentrations of the inhibitor are generally required in studies utilising the concentric probe (Damsma et al., 1987b; Marien and Richards, 1990; Herrera-Marschitz 1992). A previous set of characterization studies using a similar microdialysis preparation demonstrated that the $10 \mathrm{~mm}$ concentration of the inhibitor was the minimum concentration required for the detection of a haloperidol induced increase in $\mathrm{ACh}$ release in the fundus striati (O'Connor et al., 1991a).

Large inter-group differences in basal DA levels from the dorsolateral striatum have been reported previously (see Osborne et al., 1991 for discussion) and probably account for the large number of reports that present data as percent of control. The presentation of the raw data graphically highlights the difficulties in attempting quantitative comparison between experimental groups that present different basal transmitter levels and emphasise the importance of choosing the appropriate control. In contrast to the large inter-group variability in basal DA levels, the within group variability (i.e., control side vs neostigmine side) was low demonstrating that basal DA levels do not differ between the left and right sides.

The TTX sensitivity of basal dialysate DA levels in both the control (no neostigmine) and neostigmine treated dorsolateral striata confirms the findings of previous similar studies (Drew et al., 1989; Santiago and Westerink, 1990) and suggests that a

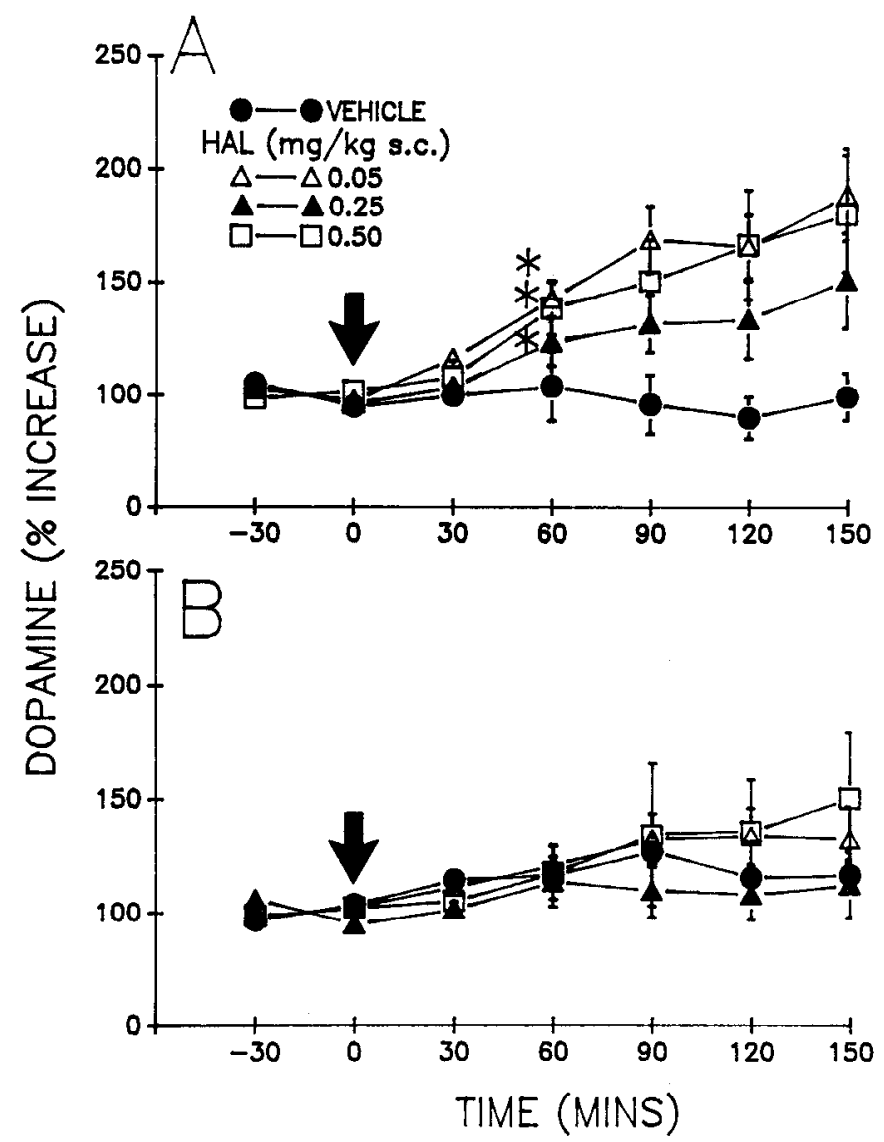

Figure 4. The effect of local perfusion with neostigmine (10 $\mathrm{MM})$ on the haloperidol $(0.05,0.25$, and $0.5 \mathrm{mg} / \mathrm{kg} \mathrm{s.c.})$ induced increase dialysate dopamine $(D A)$ levels in the dorsolateral striatum of halothane anacsthetized rats in 30 min Ringer's perfusate fractions. The perfusion medium on the left side $(B)$ contained neostigmine which was included prior to probe implantation and continued to be perfused until the end of the experiment. The contralateral side $(A)$ acted as the control. Haloperidol was administered following two stable baseline levels (commencing $120 \mathrm{~min}$ after probe implantation). The vertical arrow indicates the time of haloperidol or vehicle injection. The increase in dialysate DA levels are expressed as a percent of the mean of two basal levels prior to haloperidol. Each data point ( $N=4-7$ per group) represents the mean \pm SEM. Basal dialysate DA on the control (no neostigmine) side were (in nanomolar); $2.10 \pm 0.37,4.55 \pm 1.10$, and 3.37 \pm 0.65 for the $0.05,0.25$, and $0.5 \mathrm{mg} / \mathrm{kg} \mathrm{s.c.} \mathrm{treated} \mathrm{groups} \mathrm{and} \mathrm{were}$ maximally increased to $4.07 \pm 0.87,7.75 \pm 2.27$, and $6.40 \pm 1.62$, respectively, after haloperidol. Basal dialysate DA levels in the presence of $10 \mu \mathrm{M}$ neostigmine were; $3.10 \pm 0.17,4.12 \pm 0.95$, and $4.45 \pm$ 0.45 for the $0.05,0.25$, and $0.5 \mathrm{mg} / \mathrm{kg}$ s.c. treated groups and were maximally increased to $4.12 \pm 0.37,4.42 \pm 0.80$, and $6.82 \pm 1.42$, respectively, $180 \mathrm{~min}$ after haloperidol. Statistical analysis was performed by a two-way ANOVA followed by a Newman-Keuls post-hoc comparison (Crisp Crunch) or a $t$ test where indicated. ${ }^{*}, P<0.05$ versus prehaloperidol levels.

large fraction of basal dialysate DA levels observed in the present study is derived from impulse dependent neuronal release.

The neostigmine induced increase in basal DA levels in the fundus striati is in general agreement with in vitro and in vivo (push-pull) studies demonstrating that locally applied $\mathrm{ACh}$ increases spontaneous DA releae in rat and cat striatum (Bartholini et al., 1975; Giorguieff et al., 1977; De Belleroche et al., 1982; Lehman and Langer, 1982; Rapier et al., 1990) and with in vivo microdialysis studies which report an increase in basal DA levels following local perfusion with neostigmine $(10 \mu \mathrm{M})$ (Farber et al., 1993), the $M_{1}$ receptor agonist $A F 102 B$ (Xu et al., 1989) 

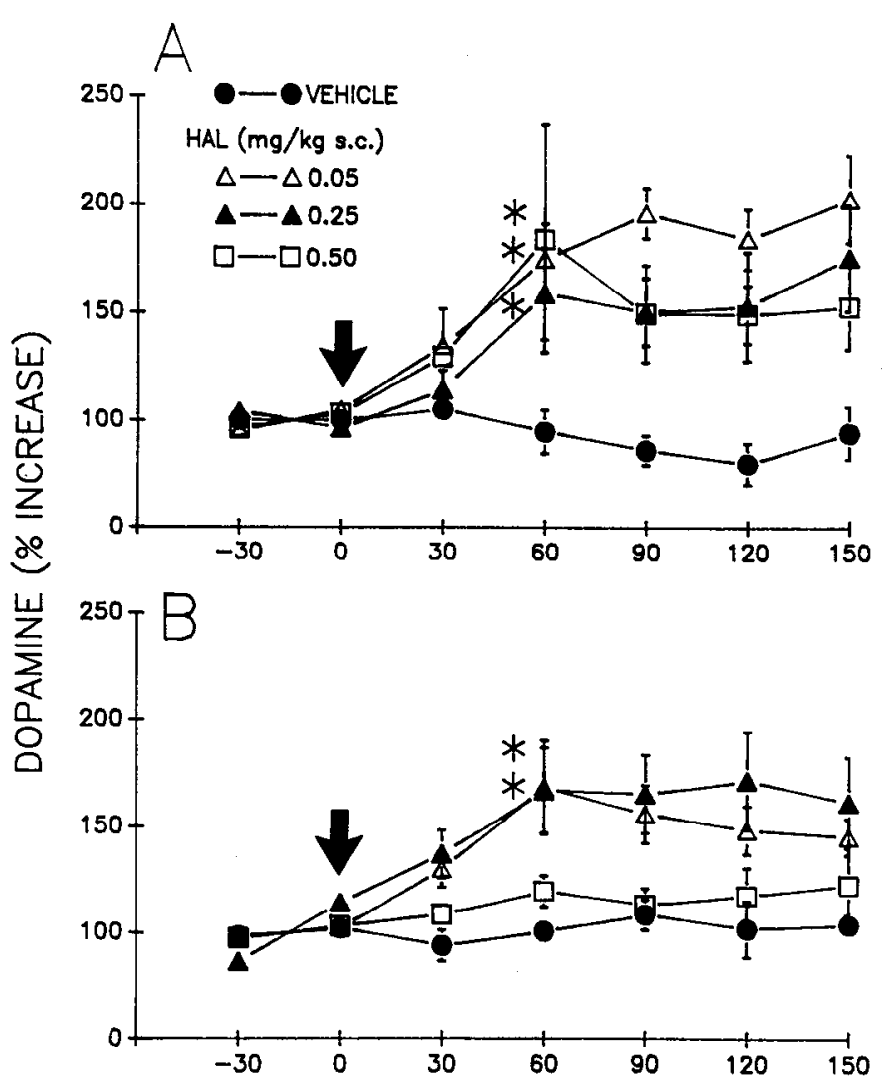

TIME (MINS)

Figure 5. The effect of local perfusion with neostigmine $(10 \mu \mathrm{M})$ on the haloperidol $(0.05,0.25$, and $0.5 \mathrm{mg} / \mathrm{kg}$ s.c. $)$ induced increase dialysate dopamine (DA) levels in the fundus striati of halothane anaesthetized rats in 30 min Ringer's perfusate fractions. The perfusion medium on the left side $(B)$ contained neostigmine which was included prior to probe implantation and continued to be perfused until the end of the experiment. The contralateral side $(A)$ acted as the control. Haloperidol was administered following two stable baseline levels (commencing 120 min after probe implantation). The vertical arrow indicates the time of haloperidol or vehicle injection. The increase in dialysate DA levels are expressed as a percent of the mean of two basal levels prior to haloperidol. Each data point ( $N=3-4$ per group) represents the mean \pm SEM. Basal dialysate DA levels on the control (no neostigmine) side were (in nanomolar); $2.02 \perp 0.35,1.20 \perp 0.40$, and $1.75 \pm 0.4$ for the $0.05,0.25$, and $0.5 \mathrm{mg} / \mathrm{kg}$ s.c. treated groups and were maximally increased to $3.90 \pm 0.52,2.40 \pm 1.1$, and $3.20 \pm 1.07$, respectively, after haloperidol. Basal dialysate DA levels in the presence of $10 \mu \mathrm{M}$ neostigmine were: $2.02 \pm 0.15,2.72 \pm 0.45$, and $4.62 \pm 1.50$ for the 0.05 , 0.25 , and $0.5 \mathrm{mg} / \mathrm{kg} \mathrm{s.c.} \mathrm{treated} \mathrm{groups} \mathrm{and} \mathrm{were} \mathrm{maximally} \mathrm{increased}$ to $3.42 \pm 0.52,6.37 \pm 1.87$, and $5.27+1.95$, respectively, after haloperidol. Statistical analysis was performed by a two-way ANOVA followed by a Newman-Keuls post-hoc comparison (Crisp Crunch) or a $t$ test where indicated. ${ }^{*}, P<0.05$ versus pre-haloperidol levels.

and systemic nicotine (Damsma et al., 1988) from an area of the striatum incorporating both the dorsal and ventral subregions and implies that this release is occurring primarily in the ventral subregion of the neostriatum. The results of the present study are also consistent with reports that both systemic and local perfusion with nicotine increases DA release in the nucleus accumbens (Imperato et al., 1986).

The selective stimulatory effects of neostigmine on basal DA release in the fundus striati may reflect the regional variability in AChE activity reported within the neostriatum (Joyce and Marshall, 1987; Loopuijt 1989) and/or a direct action of ACh

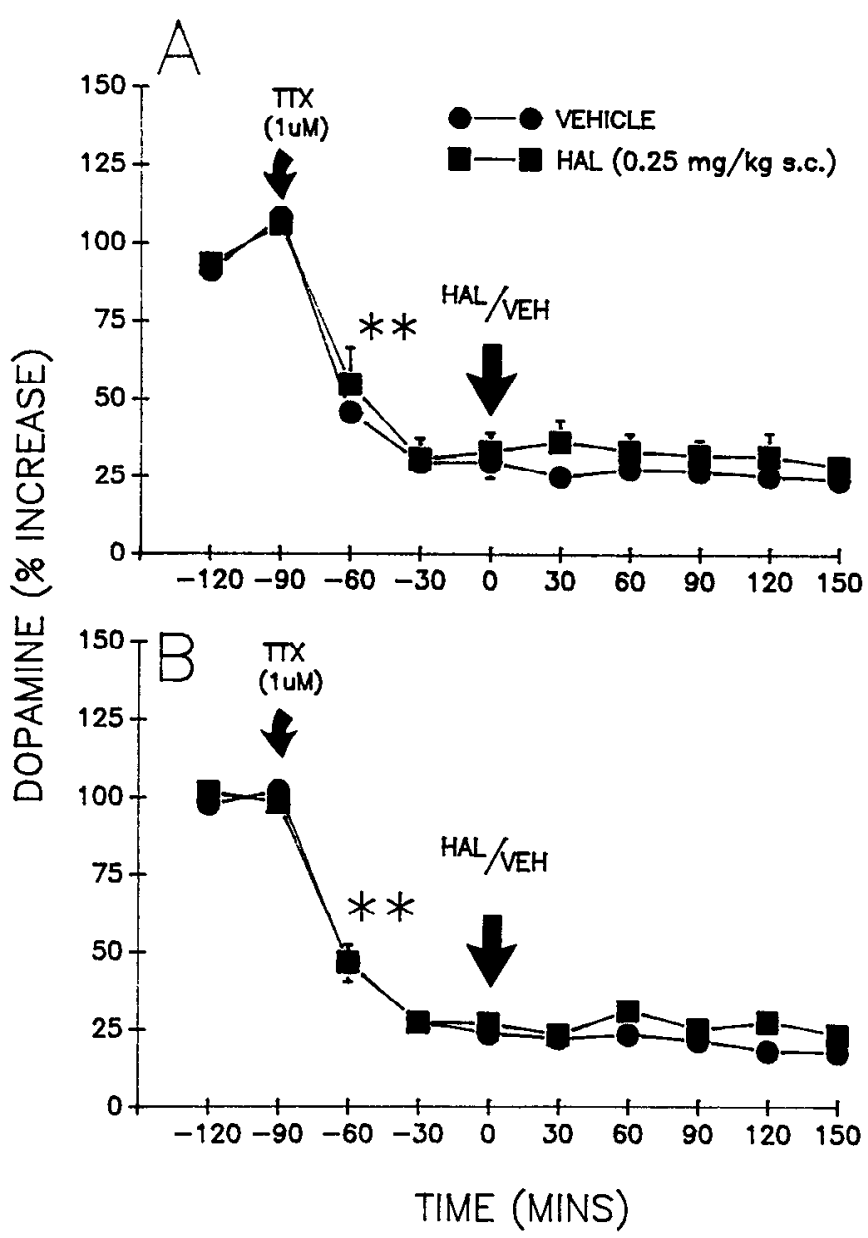

Figure 6. The effect of local perfusion with $1 \mu \mathrm{M}$ tetrodotoxin (TTX) on basal and haloperidol $(0.25 \mathrm{mg} / \mathrm{kg}$ s.c. $)$ induced increase dialysate dopamine (DA) levels in the control (no neostigmine) and contralateral neostigmine $(10 \mu \mathrm{M})$ treated dorsolateral striata of halothane anaesthetized rats in 30 min Ringer's perfusate fractions. The perfusion medium on the left side $(B)$ contained neostigmine which was included prior to probe implantation and continued to be perfused until the end of the experiment. The contralateral side $(A)$ acted as the control. TTX was locally perfused following two stable DA levels (commencing $120 \mathrm{~min}$ after probe implantation) and continued to be perfused until the end of the experiment. Haloperidol was administered 90 min after the onset of perfusion with TTX. The vertical arrow indicates the time of haloperidol or vehicle injection. Basal dialysate DA levels on the control (no neostigmine) side were (in nanomolar); $6.17 \pm 0.95$ and $4.80 \pm 0.97$ for the vehicle and $0.25 \mathrm{mg} / \mathrm{kg}$ s.c. treated groups and were reduced to $1.77 \pm 0.30$ and $2.17 \pm 0.82$, respectively, 90 min after onset of perfusion with TTX. Basal dialysate DA levels in the presence of $10 \mu \mathrm{M}$ neostigmine were; $7.10 \pm 1.32$ and $4.05 \pm 0.65$ for the vehicle and $0.25 \mathrm{mg} / \mathrm{kg}$ s.c. treated groups and were reduced to $1.30 \pm 0.15$ and $1.12 \pm 0.30$, respectively, $90 \mathrm{~min}$ after onset of perfusion with TTX. The decrease in dialysate DA levels are expressed as a percent of the mean of two basal levels prior to TTX. Each data point $(N=4-8$ per group) represents the mean \pm SEM. Statistical analysis was performed by a two way analysis of variance ANOVA followed by a NewmanKeuls post-hoc comparison (Crisp Crunch) or a $t$ test where indicated. **, $P<0.001$ versus pre-TTX levels.

on stimulatory nicotinic and muscarinic $\mathrm{M}_{1}$ receptors located on DA terminals in this striatal subregion (Xu et al., 1989; 1990). In addition, the fact that extracellular $\mathrm{ACh}$ levels are consistently higher in the dorsal compared to the ventral striatum ( $\mathrm{O}^{\prime}$ Connor et al., 1991a; Osborne et al., 1994) indicates that stimulatory muscarinic and nicotinic receptors may be already maximally activated in this striatal subregion. However, the fact that anti- 
cholinergic drugs have little effect on basal DA levels in the neostriatum either in vitro (Memo et al., 1988; Meltzer et al., 1994) or in vivo (Damsma et al., 1988) suggest the cholinergic regulation of basal DA release in this striatal subregion may be of a phasic rather than a tonic nature. Differences in the affinity and/or density of stimulatory cholinergic receptor subtypes in the neostriatum may also play a role. The selective facilitation of basal DA release in the fundus striati implies a cholinergic amplification of DA transmission which may be relevant in motivated and goal directed hehaviors as well as providing in vivo evidence for a role of limbic DA in the central action of $\mathrm{ACh}$.

\section{Effect of haloperidol on dialysate dopamine levels}

DA release in both the control (no neostigmine) dorsolateral and fundus striata were increased following all the doses of haloperidol tested. In addition, there was a similarity in the dose response profile in both striatal subregions. In the first fraction (30 min) following haloperidol, dialysate DA levels were elevated and continued to increase until the end of the experiment (150 min). Taken together, these observations suggest that the presynaptic $\mathrm{D}_{2}$ autoreceptor appears to be primarily involved in the regulation of striatal DA release (Westerink and deVries, 1989) and despite the reported difference in $D_{2}$ receptor density (Joyce and Marshall, 1987), has a similar activity in both the dorsal and ventral neostriatum. The magnitude of the haloperidol induced increase in DA release in the dorsolateral striatum was less than that observed in chronically implanted awake rats (Imperato and Di Chiara 1985; Osborne et al., 1994) and probably reflects the different methodological approaches employed, for example, probe design, anesthesia, perfusion medium etc. The TTX sensitive increase in DA release following haloperidol confirms the findings of a similar study by Drew et al. (1990) and suggests that the impulse activity of the nigrostriatal dopamine neurons is a prerequisite for the effect of haloperidol on striatal dopamine release (Bunney et al., 1973; Westerink and deVries, 1989).

\section{The effect of neostigmine on the haloperidol response}

Local perfusion with neostigmine counteracted the effects of all doses of haloperidol on $\mathrm{D} \Lambda$ release in the dorsolateral striatum but this was only observed at the highest dose of haloperidol in the fundus. This is consistent with in vitro studies demonstrating that locally applied $\mathrm{ACh}$ counteracts ${ }^{3} \mathrm{H}$-amine release evoked by potassium, electric field and nicotine stimulation in rat neostriatal slices (Westfall et al., 1974a,b) and with recent microdialysis studies indicating that activation of striatal muscarinic $M_{2}$ receptors located at least in part on DA terminals, inhibits DA release evoked by nerve stimulation (see Cheselett, 1984; $\mathrm{Xu}$ et al., 1989) and implies that this inhibition occurs dorsally (Javoy et al., 1974; Westfall et al., 1974a,b). Striatal ACh and DA also interact indirectly by converging on the medium spiny GABA neuron (Pickel and Chang, 1980) and a differential distribution of both muscarinic receptor subtypes has been recently described in the neostriatum, with increased expression of the stimulatory $M_{1}$ subtype on enkephalin containing neurons and inhibitory $\mathrm{M}_{2} / \mathrm{M}_{4}$ subtypes on substance $\mathrm{P}$ containing neurons (Gerfen et al., 1990; Le Moine et al., 1991; Bernard et al., 1992). In addition, local perfusion with neostigmine $(10 \mu \mathrm{M})$ and systemic haloperidol increases GABA release in the dorsolateral striatum (Drew et al., 1990; O'Connor et al., 1991b, 1992; Osborne et al., 1994). 'laken together, these finding suggest that the differential inhibitory action of $\mathrm{ACh}$ in the neostriatum seen in our experiments may also reflect the existence of either different subpopulations of GABA neurons exhibiting a different sensitivity to $\mathrm{ACh}$ or different neuronal loops (Xu and Kato, 1988).

\section{Differential cholinergic regulation of dopamine release in the dorsal and ventral neostriatum. Possible mechanisms and implications}

In addition to blocking the $\mathrm{D}_{2}$ receptor and thus diminishing $\mathrm{D}_{2}$ mediated transmission, haloperidol also blocks the $D_{2}$ autoreceptor resulting in an elevation of synaptic DA levels which may exert a partial overcoming effect on $\mathrm{D} \Lambda$ transmission by competing with haloperidol for at least a portion of postsynaptic $\mathrm{D}_{2}$ receptors. In the present study we demonstrate that this haloperidol induced increase in synaptic DA levels is decreased following local perfusion with neostigmine in the dorsolateral striatum which leads to a further impairment in DA transmission in this striatal subregion.

Considered in the light of evidence implicating a decrease in DA transmission in the dorsolateral striatum with the mediation of extrapyramidal side effects (Costall and Naylor, 1976), the present findings may help to relate the haloperidol induced increase in striatal ACh release (Bertorelli and Consolo 1990; Damsma et al., 1990; O'Connor et al., 1991a) with the extrapyramidal motor side effects due to the ability of striatal $\mathrm{ACh}$ to further impair DA transmission in this striatal subregion and explains why neostigmine may worsen haloperidol induced extrapyramidal motor side effects. Furthermore, the amelioration of haloperidol induced extrapyramidal motor side effects and other "striatal dopamine deficiency syndromes" (Hornykeicwicz, 1973) such as Parkinson's disease, and tardive dystonias by anticholinergics may be due in part, to a restoration of DA transmission in this striatal subregion by antagonizing the inhibitory effect of $\mathrm{ACh}$ and may explain why the newer atypical neuroleptics such as clozapine and thioridazine which have potent anticholinergic activity possess few extrapyramidal motor side effects. Furthermore, the relative lack of effect of neostigmine on the haloperidol induced increase in DA release in the fundus striati is consistent with the fact that anticholinergics do not impair antipsychotic efficacy. Taken together, these obser vations strengthen the evidence that the ventral striatum is the site of antipsychotic action of neuroleptics whereas the extrapyramidal motor side effects are produced by actions on the more dorsal regions of the striatum.

In conclusion, we provide in vivo evidence for a differential cholinergic regulation of DA release in the neostriatum and demonstrate that the facilitatory and inhibitory actions of neostigmine operate independently and have a regional specificity within the neostriatum.

\section{References}

Anden N, Stock G (1973) Effect of clozapine on the turnover of dopamine in the corpus striatum and in the limbic system. J Pharm Pharmacol 25:346-351.

Bartholini G, Stadler H, Lloyd KG (1975) Cholinergic-dopaminergic interregulation within the extrapyraniidal system. In: Cholinergic mechanisms (Waser PG, ed), pp 411-418. New York: Raven.

Bernard V, Normand E, Bloch B (1992) Phenotypical characterization of rat striatal neurons expressing muscarinic receptor genes. J Neurosci $12: 3591-3600$.

Bertorelli R, Consolo R (1990 $\mathrm{D}_{1}$ and $\mathrm{D}_{2}$ dopaminergic modulation of acetylcholine release in freely moving rats. J Neurochem 54:2145.

Besson MJ, Cheramy A, Feltz P, Glowinski J (1969) Release of newley 
synthesized dopamine from dopaminc containing terminals in the rat. Proc Natl Acad Sci USA 62:741-748.

Bunney BS, Walters JR, Roth RH, Aghajanian K (1973) Dopaminergic meurons: effect of antipsychotic drugs and amphetamine on single cell activity. J Pharmacol Exp Ther 185:560-571.

Chesselet MF (1984) Presynaptic regulation of neurotransmitter release in the brain; facts and hypothesis. Neuroscience 12:347-375.

Chiodo LA, Bunney BS (1983) Typical and atypical neuroleptics; differential effects of chronic administration on the activity of $A 9$ and A 10 dopaminergic neurons. J Neurosci 3:1670-1675.

Christensen AV, Arnt J, Hyttel J, Larsen J, Svendsen O (1984) Pharmacological effects of a specific dopamine Dl antagonist SCH23390 in comparison with neuroleptics. Life Sci 32:1529-1535.

Cooper JR (1994) Unsolved problems in the cholinergic nervous system. J Neurochem 63:395-399.

Cortes R, Palacios JM (1986) Muscarinic receptor subtypes in the rat brain. 1. Quantitative autoradiographic studies. Brain Res 362:227238.

Cortes R, Probbst A, Tobler HJ, Palacios JM (1986) Muscarinic cholinergic receptor subtypes in the human brain. 11. Quantitative autoradiographic studies. Brain Res 362:239-253.

Coatall B, Naylor RJ (1976) A comparison of the abilities of typical neuroleptic agents and of thioridazine, clozapine, sulpiride and metoclopramide to antagonize the hyperactivity induced by dopamine applied intracerebrally to areas of the extrapyramidal and mesolimbic systems. Eur J Pharmacol 40:9-15.

Dahlstrom A, Fuxe K (1964) Evidence for the existence for monoamine-containing neurons in the central nervous system. I. Demonstration of monoamines in the cell bodies of the brain stem neurons. Acta Physiol Scand 62(Suppl 232): $1-55$.

Damsma G (1987a) Microdialysis of acetylcholine from rat brain: analytical, methodological and pharmacological aspects. Ph.D. thesis, Medicinal Chemistry Group, Pharmaceutical Laboratories, University of Groningen, The Netherlands.

Damsma G, Westerink BHC, de Vries JB, Vandenberg CJ, Horn AS (1987b) Measurement of acetylcholine release in freely moving rats by means of automated intracerebral dialysis. J Neurochem 43:1523.

Damsma G, Westerink BHC de Vries LB, Horn AS (1988) The effect of systemically applied cholinergic drugs on the striatal release of dopamine and its nnelabolites, as determined by an automated brain dialysis in conscious rats. Neurosci Lett 89:349 -254.

Damsma G, de Boer P, Westerink BHC, Fibiger HC (1990) Dopamine regulation of striatal cholinergic interneurons: an in vivo microdialysis study. Naunyn-Schmiedeberg's Arch Pharmacol 324:523-527.

De Belleroche J, Luqumani Y, Bradford HF (1979) Evidence for presynaptic cholinergic receptors on dopaminergic terminals; degeneration studies with 6-hydroxydopamine. Neurosci Lett 11:209-213.

De Belleroche J, Kilpatrick IC, Birdsall NJM, Hulme EC (1982) Presynaptic muscarinic receptors on dopamine terminals in the nucleus accumbens. Brain Res 234:327-337.

Di Chiara G, Morelli M, Consolo S (1994) Modulatory functions of neurotransmitters in the striatum: $\mathrm{ACh} /$ dopamine/NMDA interactions. Trends Neurosci 17:228.

Drew KL, O'Connor WT, Kehr J, Ungerstedt U (1989) Characterization of gamma aminobutyric acid and dopamine overflow following acute implantation of a microdialysis probe. Life Sci 45:1307-1317.

Drew KL, O'Connor WT, Kehr J, Ungerstedt U (1990) Regional specific effects of clozapine and haloperidol on GABA and dopamine release in rat basal ganglia. Fur J Pharmacol 187:385-397.

Farber SA, Kischka U, Marshall D, Wurtman R (1993) Potentiation of choline of basal and electrically evoked acetylcholine release, as studied using a novel device which both stimulates and perfuses rat corpus striatum. Brain Res 607:177-184.

Gerfen CR, Engber TM, Mahan LC, Susel Z, Chase TN, Monsma FJ, Sibley DR (1990) $D_{1}$ and $D_{2}$ dopamine receptor expression of striatonigral and striatopallidal neurons. Science 250:1429-1431.

Giorguieff MF, Le Floch ML, Glowinski J, Besson MJ (1977) Involvement of cholinergic presynaptic of nicotinic and muscarinic types in the control of spontaneous release of dopamine from striatal dopamine terminals in the rat. J Pharmacol Exp Ther 200:535-544.

Graybiel AM, Besson MJ, Weber E (1989) Neuroleptic sensitive binding sites in the nigrostriatal system. Evidence for differential distribution of sigma sites in the substantia nigra, pars compacta of the cat. J Neurosci 9:326-338.

Grenhoff J, Ugedo L, Svensson TH (1988) Firing patterns of midbrain dopamine neurons: differences between $A_{9}$ and $A_{10}$ cells. Acta Physiol Scand 134:127-132.

Gurwitz D, Kloogl Y, Egozi Y, Sokolovski M (1980) Central muscarinic receptor degeneration following 6-hydroxydopamine lesion in the mouse. Life Sci 26:79-84.

Hammer R, Giachetti A (1982) Muscarinic receptor subtypes: $M_{1}$ and $\mathrm{M}_{2}$ biochemical and functional characterization. Life Sci 31:29912998.

Hornykiewicz O (1973) Dopamine in the hasal ganglia. Its role and therapeutic implications. Br Med Bull 29:172-178.

Herrera-Marschitz M, Meana JJ, O`Connor WT, Goiny M, Reid MS, Ungerstedt U (1992) Neuronal dependence of extracellular dopamine, acetylcholine, glutamate, aspartate and gamma-aminobutyric acid (GABA) measured simultaneously from rat neostriatum using in vivo microdialysis: reciprocal interactions. Amino Acids 2:157.

Hsiao JK, Ball BA, Morrison PF, Mefford IN, Bungay PM (1990) Effects of different semipermeable membranes on the in vitro and in vivo performance of microdialysis probes. J Neurochem 54:14491152.

Imperato A, Di Chiara G (1985) Dopamine release and metabolism in awake rats after systemic neuroleptics as studied by trans striatal dialysis. J Neurosci 5:297-306.

Imperato A, Mulas A, Di Chiara G (1986) Nicotine preferentially stimulates dopamine release in the limbic system of freely moving rats. J Neurosci 5:297-306.

Javoy F, Agid Y, Bouvet D, Glowinski J (1974) Changes in neostrialal doapmine metabolism after carbachol or atropine microinjections into the substantia nigra. Brain Res 68:253-260.

Jerusalinski D, Harvey AL (1995) Toxins from mamba venoms: small protein with selectivities for different subtypes of muscarinic acetylcholine receptors. Trends Pharmacol Sci 15:424 430.

Joyce JN, Marshall JF (1985) Striatal topography of D2 receptors correlates with indexes of cholinergic neuron localization. Neurosci Lett 53:127-131

Joyce JN, Marshall JF (1987) Quantitative autoradiography of dopamine $\mathrm{D}_{2}$ sites in rat caudate-putamen: localization to intrinsic neurons and not to ncocortical afferents. Neuroscience 20:773.

Koelle GB (1975) Anticholinesterase agents. In: The pharmacological basis of therapeutics, 5th ed (Goodman LS, Gilman A, eds). New York: Macmillan.

Lehmann J, Langer SZ (1982) Muscarinic receptors on dopamine terminals in the cat caudate nucleus: neuromodulation of ${ }^{3} \mathrm{H}$ doapmine release in vitro by engogenous acetylcholine. Brain Res 248:61-69.

Le Moine C, Normand E, Bloch B (1991) Phenotypical characterization of rat striatal neurons expressing the $D_{1}$ dopamine receptor gene. Proc Natl Acad Sci USA 88:4205-4209.

Loopuijt LD (1989) Distribution of D2 receptors in the rat striatal complex and its comparison with acetylcholinesterase. Brain Res Bull 22:805-817.

Marien MR, Richard JW (1990) Drug effects on the release of endogenous acelylcholine in vivo: measurement by intracerebral microdialysis and gas chromatography-mass spectrometry. J Neurochem 54 : 2016.

Mash DC, Potter LT (1986) Autoradiographic localization of $\mathbf{M}_{1}$ and $\mathrm{M}_{2}$ receptors in rat brain. Neuroscience 19:551-564.

Meltzer HY, Chai BL, Thomson PA, Yamamoto BK (1994) Effect of scopolamine on the efflux of dopamine and its metabolites after clozapine, haloperidol or thioridazine. J Pharmacol Exp Ther 268:14521461.

Memo M, Missale C, Trivelli L, Spano PF (1988) Acute scopolamine treatment decreases dopamine metabolism in rat hippocampus and frontal cortex. Eur J Pharmacol 149:367-370.

Muscholl E (1979) Presynaptic muscarine receptors and inhibition of release. In: The release of catecholamines from adrenergic neurons (Paton DM, ed), pp 87-110. Oxford: Pergamon.

Nauta WJH (1986) Circuitous connections linking cerebral cortex, limbic striatum and corpus striatum. In: The limbic system; functional organization and clinical disorders (Doane BK, Livingstone EK, eds), p 43. New York: Raven.

O'Connor WT, Drew KI, Ungerstedt U (1989) Differences in dopamine release and metabolism in rat striatal subregions folllowing clozapine using in vivo microdialysis. Neurosci Lett 98:211--215

O'Connor WT, Drew KL, Carlsson A, Ungerstedt U (1991a) Ncostigmine increases haloperidol induced acetylcholine release in rat striatal subregions. An in vivo microdialysis study. Curr Separ 10:115-116. 
O'Connor WT, Herrera-Marschitz M, I indefors N, Osborne PG, Drew $\mathrm{KL}$, Reid MS, Ungerstedt U (1991b) Dopamine-GABA interaction in the neostriatum. In: Proceedings of the 5th international conference on in vivo methods (Sept 21-24), Monitoring molecules in the neuroscience (Rollema $\mathrm{H}$, Westerink BHC, Drijfhout WJ, Groningen RG, eds), pp 93-95. Noordwijkerhout, The Netherlands.

O'Connor WT, Tanganelli S, Ungerstedt U, Fuxe K (1992) The effects of neurotensin on GABA and acetylcholine release in the dorsal striatum of the rat: an in vivo microdialysis study. Brain Res 573:209216.

Olianas MC, Onali P, Neff NH, Costa E (1982) Adenylate cyclase activity of synaptic membranes from rat striatum: inhibition by muscarinic receptor agonists. Mol Pharmacol 23:393-398.

Osborne PG, O'Connor WT, Ungerstedt U (1991) Effect of varying the ionic concentration of a microdialysis perfusate on basal striatal dopamine levels in awake rats. J Neurochem 56:452-456.

Osborne PG, O'Connor WT, Beck O, Ungerstedt U (1994) Acute versus chronic haloperidol; relationship between tolerance to catalepsy and striatal and accumbens dopamine, GABA and acetylcholine. Brain Res 634:20-30.

Paxinos $\mathcal{G}$, Watson $C^{\prime}(1982)$ The rat brain in stereotaxic coordinates. Sydney: Academic.

Pickle VM, Chan J (1990) Spiny neurons lacking choline acetyltransferase immunoreactivity are major targets of cholinergic and catecholaminergic terminals in rat striatum. J Neurosci Res 25:263-280.

Rapier C, Lunt G, Wonnacott S (1990) Nicotinic modulation of ${ }^{3} \mathrm{H}$ dopamine release from striatal synaptosomes: pharmacological characterization. J Neurochem 54:937-945.

Santiago M, Westerink HC (1990) Characterization of the in vivo release of dopamine as recorded by different types of intracerebral microdilaysis probes. Nauyn- Schmeideberg's Arch Pharmacol 324: $407-414$.

Snyder SH, Bangerjee SP, Yamamura HI, Greenberg D (1974) Drugs, neurotransmitters and schizophrenia. Science 184:1243-1453.
Spencer DG, Horvath E Jr, Traber J (1986) Direct autoradiographic determination of $\mathbf{M}_{1}$ and $\mathbf{M}_{2}$ muscarinic acetylcholine receptor disreibution in the rat brain: relation to cholinergic nuclei and projections. Brain Res 380:59-68.

Stoof JC, Drukarch B, De Boer, Westerink BHC, Groenewegen HJ (1992) Regulation of the activity of striatal cholinergic neurons by dopamine. Neuroscience 47:755.

Suga M (1980) Effect of long term L-DOPA administration on the dopaminergic and cholinergic (muscarinic) receptors of the striatum in 6-hydroxydopamine lesioned rats. Life Sci 27:877-882.

Ungerstedt U (1991) Introduction to intracerebral microdialysis. In: Microdialysis in the neurosciences (Robinson TE, Justice JB, eds), pp 81-105. Chichester: Wiley.

Westerink BHC, de Vries JB (1989) On the mechanism of neuroleptic induced increase in striatal dopamine release: brain dialysis provides evidence for mediation by autoreceptors localized on nerve terminals. Neurosci Lett 99:197-202.

Westfal TC (1974a) Effect of nicotine and other drugs on the release of ${ }^{3} \mathrm{H}$-dopamine from rat brain slices. Neuropharmacology 13:693700 .

Westfal TC (1974b) Effect of muscarinic agonists on the release of ${ }^{3} \mathrm{H}-$ norepinephrine and ${ }^{3} \mathrm{H}$-dopamine by potassium and electrical stimulation from rat brain slices. Life Sci 14:1641-1652.

Whitc FJ, Wang RY (1983) Differential effects of classical and atypical antipsychotic drugs on $A_{9}$ and $A_{10}$ dopamine neurons. Science 221: 1054-1059.

$\mathrm{Xu}$ M, Kato T (1988) Brain dialysis: changes in the activities of dopamine neurons in rat striatum by perfusion of acetylcholine agonists under freely moving conditions. Neurochem Int 12:539-545.

Xu M, Mizobe F; Yamamoto 'I; Kato I' (1989) Differential effects of $\mathrm{M}_{1}$ and $\mathrm{M}_{2}$ muscarinic druds on striatal dopamine release and metabolism in freely moving rats. Brain Res 495:232-242.

Xu M, Kato T, Nakamura Y (1990) In vivo striatal dopamine release by TRH analogue YM-14673 is blocked by $M_{1}$ muscarinic receptor antagonists. Neurochem Int 16:281-285. 